Cramer, Elizabeth., \& Orkiszewski, Paul. (2010). Cataloging Serials for Special Collections: The Challenges and Delights of the W.L. Eury Appalachian Collection. Serials Librarian, 59(1), 101-110. [ISSN: 0361-526X ] DOI: 10.1080/03615260903534833

\title{
Cataloging Serials for Special Collections: The Challenges and Delights of the W.L. Eury Appalachian Collection
}

\author{
ELIZABETH CRAMER and PAUL ORKISZEWSKI \\ Carol Grotnes Belk Library, Appalachian State University, Boone, North Carolina, USA
}

\begin{abstract}
Cataloging serials in special collections proves to be both a challenge and a delight. Rare, ephemeral, or older serials may contain less descriptive information than is normally found in major current periodicals, making it difficult to record such descriptive information as frequency/regularity of publication and volume designation. But the true challenges in cataloging these materials are often due to their limited and sporadic acquisition, which causes problems in describing the serials and recording boldings, resulting in more time and higher cost per issue cataloged.
\end{abstract}

KEYWORDS special collections, serials cataloging, W.L. Eury Appalachian Collection

Librarians who catalog print serials for special collections will tell you that they have one of the most interesting and challenging cataloging jobs available. What makes our jobs so exceptional is the diversity and originality of materials collected, with a much wider range of items being acquired than for the main collection. In this article, the term "special collections" will refer to collections that have a limited scope and a definite purpose. Special collections may be created to focus on a specific subject, person, or geographical location. Often the inclusiveness of the collection is limited only by budget and personnel available to process materials. Items are acquired through a variety of methods: they may be purchased through book vendors, donated, or picked up at a newspaper stand or kiosk at a local restaurant. Many of these "special" items are older, rare, or ephemeral in nature (not originally 
intended for retention) such as college commencement programs, train schedules, and seed catalogs. While these items can prove to be invaluable to the researcher, they also can be challenging to the cataloger.

In this article, the authors will be drawing on their experience cataloging serials for the W.L. Eury Appalachian Collection at Appalachian State University. The mission of the Appalachian Collection is to strive to collect, preserve, and provide public access to primary and secondary source materials for the Southern Appalachian region with an emphasis on history, culture, and politics. Currently the Appalachian Collection has more than 450 processed archival collections; 5,300 microfiche; 11,000 microfilm reels; 38,800 volumes of books; and 161 ongoing subscriptions to print serials. ${ }^{1}$ In addition to these serials received through subscription, the collection includes a wide variety of other serial items such as individual copies of 19th- and 20th-century newspapers, local tourist and real estate publications, poetry zines by local university or high school students, and catalogs from general stores, seed companies, and livestock supply merchants. These serials prove to be a challenge to catalog due to their lack of standardization in publishing, their sporadic means of acquisition, and their ephemeral/rare nature.

In this article we will discuss a number of challenges we have faced in cataloging serials for special collections and our proposed solutions to these challenges based on rules and guidelines from the CONSER Cataloging Manual and the Anglo-American Cataloguing Rules, 2nd edition, revised (AACR2r). We will also present a statistical analysis of our print serials in the Appalachian Collection and compare this data with that of our print serials in the main collection.

\section{PRE-CATALOGING DECISIONS REGARDING DESCRIPTIVE GUIDELINES}

A variety of descriptive guidelines are available for cataloging serials in special collections. Appalachian State University Library, although not a member of CONSER, has chosen to follow the cataloging and editing guidelines in the CONSER Cataloging Manual and the AACR2r. An alternative option for cataloging serials in special collections is the Descriptive Cataloging of Rare Materials (Serials) (DCRM(S)). This set of descriptive guidelines may be used for any print serial regardless of age or method of production, but it is especially pertinent to materials created before the introduction of machine printing in the 19th century. Since these items were printed before standardization of materials was the norm, they may require special notes to record variations between copies of material (missing pages, different fonts, etc.). In considering the possible application of $\operatorname{DCRM}(S)$ to the serials in the Appalachian Collection, we found the following guidelines helpful as 
written in the introduction to $\operatorname{DCRM}(\mathrm{S})$, under the section entitled: X. Precataloging Decisions.

\begin{abstract}
Institutions may promote efficiency by setting cataloging policies for specific categories of materials in their collections rather than making decisions on an item-by-item basis. For example, an institution may decide to catalog all pre-1830 serials using DCRM(S), trace printers and booksellers for all pre-18th-century serials, but give signature statements and expansive descriptive notes for 17 th-century serials only. It may choose to catalog all later serials according to AACR2, but add selected genre/form or provenance name headings. ${ }^{2}$
\end{abstract}

As the vast majority of serials in the Appalachian Collection are typical modern publications, with virtually no serials printed before 1830, we have decided to work mainly within the CONSER Cataloging Manual and AACR2r guidelines, although we do refer to DCRM(S) for guidance in local notes pertaining to provenance. We also use the RBMS Controlled Vocabularies to assign genre and provenance headings. Genre headings for Appalachian Collection serials include Ephemera to describe "transient everyday items, usually printed on paper, that are produced for a specific limited use and then often thrown away" 3 (and a number of its narrower terms-Catalogs, Programs, Schedules, and Blank Forms), as well as Calendars, Conference Programs, Guidebooks, Souvenir Programs, Zines, and University Catalogs. We also find that particular controlled vocabulary terms for provenance are helpful in identifying the former ownership and/or history of an item, terms such as Marginalia, Author's Autographs, and Author's Inscriptions.

\title{
PUBLISHING NORMS (OR LACK OF . . . )
}

The publishers of serials in the Appalachian Collection range from wellknown, established publishing houses to small, independent publishers to individuals who publish using mimeograph machines or photocopiers. Publishers vary in their knowledge and/or use of publishing norms, resulting in a lack of consistency between issues. The title may vary, there may be no volume designation or date, or the place of publication and/or publisher may not be mentioned. These problems are made more complicated when coupled with sporadic or limited acquisitions of these materials. One example from the Appalachian Collection of a title variation is the West Virginia Writers Newsletter. Each of the three issues of this serial we own has a different title: West Virginia Writers Newsletter (Summer/Fall 1991); WVW News (Winter 1996); and WV Writers Newsletter (Summer 2007). Each requires a separate bibliographic record. To further complicate title access to this particular publication, the fact that we own only three issues with 
spans of five and eleven years apart makes it difficult to establish linking relationships between the bibliographic records. As we are unsure whether there were additional title changes between these long spans of dates, we are unable to establish chronological relationships (MAchine-Readable Cataloging [MARC] fields 780, 785) between the title variations. The decision not to include such links in the records is in accordance with section 14.5.1 of the CONSER Cataloging Manual, which states that such links should not be made when

a record is found in the database which appears to be related sequentially to the title being cataloged but there are no dates in the record and it is unclear whether the publication preceded or succeeded the publication being cataloged or whether there have been intervening changes. ${ }^{4}$

Imprint information (place of publication, publisher, and year(s) of publication) makes it easier to match serials with the appropriate bibliographic records, particularly when the serials have similar titles. It seemed that a surprisingly large number of serials in the Appalachian Collection lacked a stated place of publication or publisher. Twenty-five percent of the print serials in the Appalachian Collection ( 434 out of 1,817 ) do not contain a stated place of publication; their bibliographic records instead include a supplied place of publication (a probable place of publication, even if it is only at the state or country level) or if we do not know even the country of publication, we include "[S.I]" (sine loco). Surprisingly, in comparing these statistics to the serials in the main stacks, the number of serials without a stated place of publication is markedly similar. In the main stacks, 26 percent (1463 out of 5676) of serials lack a stated place of publication. Even more surprising, publisher information appeared more frequently in the Appalachian Collection serials, with only 16 percent (297 out of 1,817) of the Appalachian Collection serials needing publisher information supplied or "[s.n.]" (sine nomine), in comparison with 26 percent $(1,452$ out of 5,676$)$ of serials in the main stacks.

The lack of useful descriptive information can be frustrating at times, but it is by no means uncommon. An interesting example of the omission of publishing information is the literary magazine entitled Help Yourself. The Appalachian Collection purchased a single issue of this serial from a rarebook dealer. The issue has the title on the cover and the following note on the first page: "This memorial edition of Help Yourself is dedicated to Gordon Browning, 1938-1982, who taught at Eastern Kentucky University from 1966-1982, who founded and edited Help Yourself from 1974 until his death." ${ }^{5}$ There is no stated place of publication, publisher, date, or volume designation. If this serial had required original cataloging, the fixed field data for regularity, frequency, date type, and dates would all have been unknown. Publishing information in the 260 MARC field would most likely 
have contained "[Kentucky: Eastern Kentucky University?]". The record likewise would have lacked a 310 MARC field (current publication frequency) and a 362 MARC field (dates of publication and/or sequential designation). Fortunately, a member record did exist in Online Computer Library Center, Inc. (OCLC) that named Gordon Browning as editor. In addition, it included "Berea, Ky.: Berea College" as the imprint, something we could never have determined from the one issue we own.

Many of these publishers do not include information about the frequency of their serials. To further complicate the matter, when we receive only one issue of a serial with no stated frequency, we lack the ability to make an assumption about frequency based on evidence from previous issues. The result is a surprising number of serials that include a " $u$ " (for "unknown") in both the frequency and regularity fixed fields and have no 310 MARC field stating the current frequency. Thirty-two percent ( 578 out of 1,817 ) of our serials in the Appalachian Collection do not include a 310 MARC field as opposed to only 12 percent (702 out of 5,676) in our main stacks. Many smaller publishers also fail to maintain their publication schedules due to a lack of personnel, financial support, and/or sufficient planning. There are serials for which the actual frequency does not match the projected frequency stated on the first issue. Publishers fall behind schedule, perhaps due to lack of funding, staffing, time, or continued interest. One refreshing frequency statement, blunt in its honesty, comes from Step by Step: Creative Expression by West Virginia Youth-"Step by Step is published three or more times per year (depending on contributions and funding)."

Serials that lack adequate descriptive information demand informative notes and extensive subject analysis. As many libraries do not classify their serials, subject headings are extremely important access points. Recently we received a local poetry zine with no title (we were unable to tell if it had been published without a title or if the title page was missing). The item was accompanied by a handwritten note, "Watauga H.S. publication, no other info., 2003?" For this serial we have no stated place of publication, publisher, dates, volume designation, or title. The value for researchers is that it is a collection of poetry written by local gay youth at Watauga High School in Watauga County, North Carolina. The principal access to this serial is through subject entries: the name of the high school as well as the headings 'High school students' writings, American-North CarolinaWatauga County" and "Gay high school students—Poetry."

With the increase in online and desktop publishing, it is becoming more common for a specific person to be listed as publisher. For instance, many of our genealogical, community, and activist newsletters are published by individuals. An example is CTQ: A Journal of Culture, Ideas, and Interesting People. On the verso of the title page is found the statement "Dr. Sonya Jones, Publisher and editor." "We often include the name of a person associated with a serial as an inferred publisher (with the name in brackets) 
when no commercial publishing or printing firm is mentioned. Section 10.2.2 of the CONSER Cataloging Manual provides direction regarding the recording of individuals as publishers. It states

A person is recorded as the publisher only when he or she is named as the publisher and is acting alone and not as the representative of a firm. ... When recording the name of a person as publisher, the first names have traditionally been abbreviated to the first initials, but the full form of name may also be given. Do not record as a publisher persons whose job title is "publisher" when there is a commercial publishing company. ${ }^{8}$

\section{ADDITIONAL TIME AND STAFFING REQUIRED}

As is to be expected by the type of materials collected for the Appalachian Collection, many more of the print serials require original cataloging than those serials in the main stacks. Local publications such as high school yearbooks and ephemera such as product catalogs, tourist and real estate publications, and local event bulletins most likely have not yet been cataloged by other institutions. Surprisingly, few of the literary magazines by area colleges and universities have been cataloged. This is in a direct contrast to the serials in the library's main stacks. Almost one in four (24 percent, 434 out of 1,817) print serials in the Appalachian Collection required original cataloging. Only 0.05 percent (three out of 5676) serial titles in our main stacks required original cataloging. The vast majority of the serials in the Appalachian Collection lack ISSNs, making access by ISSN impossible. Only 28 percent $(503$ out of 1,817$)$ of these serials have ISSNs compared with 89 percent $(5062$ out of 5,676$)$ of the print serials in the main stacks. The cost in cataloging the Appalachian Collection serials, considering the time it takes for a professional cataloger to create original bibliographic records, is substantially higher. It would cost approximately $\$ 33$ in salary and benefits for a serial to be cataloged by an experienced cataloger making $\$ 60,000$ a year (based on one serial cataloged per hour). That cost per item combined with other physical processing costs must be considered in the institutional decision to acquire and process special collection materials.

We often receive a limited number of issues of a serial's run, as opposed to the longer runs of serials in the main stacks. This may be due to two factors: (1) we have acquired (either through purchase or donation) limited or single issues of a serial, or (2) a periodical that was published for only a brief period of time. Items such as local travel/real estate/lifestyle serials, often ephemeral and with abundant local advertising, may cease publication within a year while new publications are created to replace them. Non-profit publications, particularly those created by individuals or by genealogical or small non-profit activist agencies, may cease publication after 
only one or a few issues. These situations result in a higher percentage of serial records with fewer items attached. This then translates to a higher cost per issue since more time and bibliographic records are needed for the processing of fewer issues. In the Appalachian Collection, 80 percent of the 1,817 serial bibliographic records have five or fewer item records attached; of that portion, 42 percent have only one item attached. In contrast, 78 percent of main stacks records have six or more attached item records (see Table 1). As a result, in the main stacks we can set up a serial record and expect to add regularly received volumes that can be processed by lower level staff or student labor. In the Appalachian Collection, on the other hand, we are continually adding new serial records with a high proportion of original cataloging performed by high-level professional staff.

Since the aim of our special collections is to collect and make available the most valuable primary and secondary source materials for the Southern Appalachian region, we catalog many more items as component parts than do most cataloging departments. We often catalog single issues of a serial, individual articles, and even illustrations separately at the analytic and "in-analytic" level, the latter in accordance with Rule 13.5A of AACR2r, which states, "If more bibliographic description is needed for the part than can be obtained by displaying it in the note area, make an 'In' analytic entry." We have cataloged special bicentennial issues of local newspapers, articles about Appalachian celebrities published in popular culture magazines, and individual color prints from such 19th-century weeklies as Harper's Weekly and Frank Leslie's Illustrated Newspaper. We have acquired complete issues of the 19th-century newspaper The Boston Recorder in order to catalog individual articles about the Moravian mission in the Cherokee Nation, North Carolina.

In instances such as these, when we own the complete issue of a print copy of a rare newspaper or journal, we also generally download the MARC serial record from OCLC and add our holdings to the MARC serial record there. Although the majority of these historical items are not available for interlibrary loan, we realize the value of owning original print copies of these issues and feel obliged to include detailed holdings information in our local online system. The serial record may contain additional access points not found in the corresponding analytic record. The decision to download

TABLE 1 Number of Item Records Attached to Bibliographic Records for Serials in the Main Stacks and Appalachian Collection

\begin{tabular}{|c|c|c|c|c|c|}
\hline & \multicolumn{5}{|c|}{$\begin{array}{l}\text { Number of item records attached to } \\
\text { bibliographic records }\end{array}$} \\
\hline & 0 & 1 & $2-5$ & $6-10$ & $10+$ \\
\hline Main stacks (5,676 titles) & $0 \%$ & $6 \%$ & $16 \%$ & $15 \%$ & $63 \%$ \\
\hline Appalachian Collection (1,817 titles) & $10 \%$ & $42 \%$ & $28 \%$ & $10 \%$ & $10 \%$ \\
\hline
\end{tabular}


the serial record and attach our holdings is, however, made on a case-by-case basis. For instance, when we obtained a single issue of No Depression, a magazine for the alternative country music scene, because we wanted the article on Lucinda Williams, we did not download the serial record.

\section{SPORADIC ACQUISITION}

Receiving issues sporadically through various avenues makes it difficult to catalog and process a run of issues. To analyze the various means of serials acquisition in the Appalachian Collection versus the main stacks, we examined those serial records in our system that had purchase orders attached. Purchase orders are used both for serials received as firm orders (one-time purchases without a subscription or scheduled receipt) and for serials received on subscription. A total of 1,332 serials in the Appalachian Collection and 3,024 serials in the main stacks had purchase orders attached. As Table 2 illustrates, 83 percent $(1,110$ out of 1,332) of the Appalachian Collection serials were purchased or received as firm orders. Only 17 percent (222 out of 1,332) of the Appalachian Collection serials were received through active or closed subscriptions. This is in direct comparison to the serials in the main stacks, 97 percent of which (2,942 out of 3,024) were received as subscriptions. As with the number of attached item records per bibliographic record, the end result is more time spent per serial title, and therefore a higher cost per serial in the Appalachian Collection.

In addition to those challenges already mentioned, other problems arise related to sporadic acquisition of serials. We may catalog one issue of a serial, only to receive the first issue or a stack of additional issues the following month. In this case we follow the CONSER editing guidelines for use in our local system, updating the record to include the information from the first issue. Or we may need to create a new record or download an additional record from OCLC if there is a major change in title or other change that requires a new record. A decision must occasionally be made whether to catalog issues as they arrive or to wait until additional issues are received as donations or purchases, or, in some cases, are discovered in the backlog. We have found that taking the time to gather and sort the serials

TABLE 2 Firm Orders and Subscriptions, Serials in the Main Stacks and the Appalachian Collection

\begin{tabular}{lrc}
\hline & Main stacks & Appalachian collection \\
\hline Firm order & 82 & 1,110 \\
Active subscription & 1,889 & 161 \\
Closed subscription & 1,053 & 61 \\
TOTAL & 3,024 & 1,332 \\
\hline
\end{tabular}


backlog is well worth the time, cutting down on frustration caused by stray issues being found.

If one binds special collections serials, the problems only increase. All items in our open stacks are eventually bound for preservation purposes. It is painful to make the decision to bind the partial holdings of a journal only to receive missing issues at a later date. If we choose to bind items together but only have sporadic issues, it makes it virtually impossible to record the volume information in the call number or on the spine of the bound volume. In such cases we rely on our serial check-in records to reflect our full holdings.

\section{CONCLUSION}

We have found that cataloging serials in special collections is more interesting and challenging than cataloging widely received, current serials. But it is only after writing this article that we understand the specifics of what makes them extraordinary. We were surprised to find that place of publication and publisher information was actually recorded more frequently in the Appalachian Collection serials than for the main stacks serials. But conversely, frequency statements appear less often for the Appalachian Collection titles. Our assumption had been that these smaller, non-professional publishers were unaware of publishing norms and this made these items more difficult to catalog and process. But in reality, we now realize that the true challenges arise due to the extent that these items are acquired and their limited and sporadic acquisition. These two factors result in more time and higher cost per issue cataloged and a bigger challenge in describing the serials and recording our holdings.

Yet it is these very qualities - the rareness, originality, and quirkiness of these items - that makes them such a joy to catalog. Cataloging the high school yearbook of a co-worker, the store catalog of a local long-time merchant, or an individual issue with personal notes from a historical figure has an added interest not found in cataloging major currently published journals.

\section{NOTES}

1. "Appalachian Collection at Belk Library," http://www.library.appstate.edu/appcoll/index.html (accessed 2 Feb 2009)

2. Association of College and Research Libraries. Rare Books and Manuscripts Section. Bibliographic Standards Committee, Descriptive Cataloging of Rare Materials (Serials). (Accessed from Cataloger's Desktop, August 20, 2009.)

3. Association of College and Research Libraries. Rare Books and Manuscripts Section. Bibliographic Standards Committee, RBMS Controlled Vocabularies, http://www.rbms.info/committees/ bibliographic_standards/controlled_vocabularies/genre/tr54.htm (accessed 20 Aug 2009) 
4. Cooperative Online Serials (CONSER), CONSER Cataloging Manual. (Accessed from Cataloger's Desktop, August 20, 2009.)

5. Help Yourself, Memorial issue, date unknown, p. 1.

6. Step by Step, Spring, 1990, p. 7.

7. CTQ, Winter, 2005 , p. 2.

8. Cooperative Online Serials (CONSER), CONSER Cataloging Manual.

9. Joint Steering Committee for Revision of AACR. Anglo-American Cataloguing Rules, 2nd edition, revised. (Accessed from Cataloger's Desktop, August 20, 2009.) 